\title{
Primeras Jornadas de Primavera: Alergia Respiratoria Clínica Práctica
}

\section{First Spring Meeting: Respiratory Allergy in Clinical Practice}

Los días 29 y 30 de agosto de 2014 se realizaron las Primeras Jornadas de Alergia Clínica Práctica de la Sociedad Chilena de Enfermedades Respiratorias.

En estas Jornadas contamos con 26 docentes Broncopulmonares, Inmunólogos y Otorrinolaringólogos, que actualizaron la situación de las alergias respiratorias y temas relacionados, sobre los cuales, haremos algunos comentarios.

La prevalencia de las enfermedades alérgicas está en aumento en países desarrollados y en desarrollo, por lo cual este tema debe ser enfrentado como un importante problema de salud por su alto costo y alteración de la calidad de vida de la población. Se requiere un buen reconocimiento clínico, diagnóstico oportuno, tratamiento efectivo y prevención, en una acción coordinada por personal de la salud.

Las enfermedades alérgicas pueden afectar cualquier órgano, a cualquier edad y es un desafio para el equipo médico de todas las especialidades ya que pueden poner en riesgo la vida en el caso de anafilaxia.

Actualmente se estima que las enfermedades alérgicas afectan a 1 billón de personas en el mundo y se proyecta una prevalencia de 4 billones para el año 2050.

La predisposición hereditaria o atopia es una condición de riesgo para desarrollar rinitis, asma o eczema, las que se consideran enfermedades multifactoriales y poligenéticas.

La interacción entre el sujeto con predisposición genética y el medio ambiente, determina una sensibilización inicial y posteriormente, la expresión de la enfermedad que se inicia precozmente en los primeros 3 meses de vida con la alergia por alimentos, luego los ácaros, animales domésticos, pólenes y hongos.

La prevalencia de alergia alimentaria es 6 a 8\% en niños y se debe a leche, huevo, soya, mani, y trigo, en adultos alcanza a un 4\% frente a pescados, mariscos, maní, nueces, frutas, verduras y semillas.

Se debe sospechar alergia alimentaria en pacientes con asma y urticaria, angioedema, dermatitis atópica.

La exposición a alergenos del gato desde el nacimiento y en el primer año de vida, tiende a producir tolerancia inmunológica específica para ellos, en cambio la exposición a alergenos de perro en ese mismo periodo, induce un mecanismo de tolerancia más general para otros alergenos, lo que posiblemente se deba a las endotoxinas.

La exposición a ciertos factores de riesgo, especialmente en la segunda mitad del embarazo, pueden alterar la expresión de genes en el periodo intrauterino y estos cambios serían heredables, lo que ha estimulado el desarrollo de la disciplina llamada Epigenética. 
Se mencionan como factores de riesgo el estrés, polución ambiental, tabaco, dieta y alteración de la microbiota intestinal por antibióticos. La interacción entre el sistema inmune y la microbiota intestinal, de acción inmunomoduladora para inflamación o tolerancia, juega un rol esencial en el desarrollo de células efectoras versus células T reguladoras respectivamente.

En relación a la polución ambiental, hay que considerar también, que la exposición a PM $M_{2,5}$ intradomiciliario, generado por humo de tabaco y artefactos contaminantes del hogar de limpieza y cocina, polvo doméstico, puede ser superior al que hay fuera de la casa, donde las medidas de control a este nivel son muy importantes.

La laringe órgano limitrofe entre la vía aérea superior y la inferior, fue de gran interés y generó debate. Dado que una de sus funciones es protectora y la laringe está ricamente inervada, sus receptores responden a variados estímulos como estrés, emociones, irritantes, reflujo faringo-laríngeo, virus, alergia o torsión cervical, desencadenando laringoespasmo, tos, disfonía, carraspeo/globus. Este proceso altera el equilibrio a nivel del sistema nervioso central, pudiendo co-existir con otros cuadros clínicos como colon irritable, síndrome de fatiga crónica, fibromialgia y síndrome de las piernas inquietas.

Un marcador útil en el diagnóstico de laringe irritable es el $P C_{25}-M I F_{50}$ en no asmáticos y con enfermedad inflamatoria de vías aéreas superiores.

La rinosinusitis recurrente, plantea un dilema en su diagnóstico diferencial con la rinitis alérgica o el resfrío común.

La prevalencia de la rinosinusitis aguda es de 6 a 15\% y en su gran mayoría son resfriados virales y sólo 0,5 a 2\% desarrolla sobreinfección bacteriana con sintomas persistentes por más de 10 días.

La rinosinusitis aguda recurrente, se produce cuando hay 4 ó más episodios de infección bacteriana en un año, con períodos intermedios asintomáticos, lo que es infrecuente y se produce sólo en 0,035\% de los casos.

Son factores de riesgo, la inflamación alérgica, el humo del tabaco y la contaminación ambiental ya que pueden alterar el barrido mucociliar, por lo cual se sugiere el uso de tratamiento antialérgico mantenido y lavados nasales de alto volumen con suero fisiológico.

Un tema debatido fue la bronquitis obstructiva en niños, la que es habitualmente viral, siendo VRS y Rinovirus los más importantes y en niños atópicos, estos serían factores de riesgo para desarrollar asma, y en general los virus se han asociado con exacerbación de asma tanto en niños como adultos.

Los sintomas de bronquitis en el adulto, pueden durar hasta 3 semanas en el 50\% de los casos y no se recomienda el uso rutinario de corticoesteroides inhalatorios y los antibióticos no deben ser la opción terapéutica inicial excepto si la etiología es Bordetella Pertussis.

Otro aspecto interesante de las Jornadas, fue el tema de los deportes y la evaluación cardio-respiratoria. El broncoespasmo inducido por ejercicio (BIE) se presenta en el $90 \%$ de los sujetos asmáticos y en el $20 \%$ de los portadores de rinitis alérgica. Cinco a $20 \%$ de las personas sanas también pueden presentar BIE. En los atletas de elite, se presenta en un 30 a $70 \%$ y la atopia se considera un factor de riesgo para su desarrollo. Una reducción mayor al $10 \%$ del $V E F_{1}$ después de 30 min de un ejercicio estandarizado se considera suficiente para establecer diagnóstico de BIE. La inhalación de un agonista $\beta_{2}$-adrenérgico de acción corta, 15 min antes del ejercicio es la primera medida terapéutica.

Toda la población conoce casos de deportistas que han fallecido durante su desempeño y esto ha generado preocupación. La incidencia de muerte súbita se estima entre 0,5 a 2/100.000 atletas al año y es secundaria a enfermedad cardiovascular asintomática, siendo las miocardiopatías las más frecuentes. 
La indagación de antecedentes familiares, una buena historia clínica y examen físico y un ECG son elementos útiles, pero en general, está claro que no es posible predecir, quien puede tener una muerte súbita durante un ejercicio.

El evento más extremo de la reacción alérgica es la anafilaxia, siendo su incidencia entre 21 y 103 casos por 100.000 habitantes al año, y el grupo más afectado los niños menores de 4 años.

Hacer ejercicio post ingestión de alimentos con trigo (5-gliadina) tiene alto riesgo de anafilaxia. Debemos recordar, que el uso de adrenalina debe ser siempre intramuscular.

En el ámbito del diagnóstico inmunológico, se revisaron las técnicas de Prick test e IgE específicas por diferentes metodologías, llegando a nivel molecular para identificar sensibilizaciones relevantes.

Excelentes presentaciones se realizaron en temas de diagnóstico funcional respiratorio en adultos y niños. Ambos temas, diagnóstico inmunológico y función pulmonar, fueron complementados con demostraciones prácticas con vídeos.

La prevención en enfermedades respiratorias, sean o no alérgicas, juega un rol muy importante al momento de definir las estrategias terapéuticas.

Los contaminantes ambientales, $M P_{10}, M P_{2,5}$, partículas derivadas del diésel, ozono, $\mathrm{NO}_{2}$ y humo de cigarrillo pueden exacerbar síntomas respiratorios con diferentes grados de severidad y facilitar la sensibilización a aeroalergenos.

En general hay que evitar, en lo posible, la exposición a alergenos intra y domiciliarios como ácaros, pólenes, caspa de animales y otros, aunque no siempre es fácil y efectivo.

En relación a la terapéutica, se destacaron las presentaciones sobre el uso de diferentes tipos de inhaladores y aero-cámaras en niños y adultos, y el avance que ha significado disponer de las nuevas formulaciones de corticoides inhalatorios, que se usan una vez al dia, como furoato de mometasona, ciclesonida y furoato de fluticasona.

En el asma de difícil control, se dispone de una Anti-IgE, el Omalizumab, que ha demostrado en pacientes con periostina aumentada, lograr su estabilización, mejoría en calidad de vida y reducción o suspensión de la terapia esteroidal. Los ensayos consideran un periodo de observación de 4 meses para evaluar eficacia.

La Inmunoterapia es otra de las alternativas terapéuticas especialmente en rinitis alérgica. Se comentó la eficacia y seguridad de la vía sublingual, considerando que los pacientes deben estar bien seleccionados y tratados por especialistas en el tema.

Un tema muy actual es el rol que tendría el déficit de Vitamina $D(<50 \mathrm{nmol} / \mathrm{L})$ en el aumento de varias enfermedades, entre ellas el asma bronquial. Su acción inmunomoduladora se realizaría por medio de la inhibición de células Th2 e IL-17 y estimulación de IL-10. Se estima que casi la mitad de la población tiene déficit de Vitamina D debido a que nos protegemos del sol y usamos bloqueadores solares para evitar el cáncer de piel.

Aún faltan evidencias para su recomendación rutinaria en el asma bronquial.

Al término de estas Jornadas de Primavera se analizó el tema "Asma y Plan Auge". Es importante recordar que "comete un delito el profesional o la organización de salud que no informara al paciente de sus derechos y no lo refiera al organismo prestador con el documento de constancia". 
Los asmáticos con síntomas persistentes con más de 6 meses de evolución y espirometría confirmatoria, pueden acogerse a esta ley que garantiza acceso, oportunidad, protección financiera y calidad, tanto para los pacientes del Sistema Público como Privado de Salud.

Estas Jornadas de Primavera en Alergia Respiratoria Clínica Práctica, se han realizado gracias a un excelente grupo de docentes, a quienes expresamos nuestros agradecimientos.

Dra. Liliana Vicherat Mauro

Coordinadora General

Jornadas SER de Primavera

Email:lvicheratm@yahoo.com 